\title{
DESIGNING COLLABORATIVE RESEARCH: THE EXPLORATION OF COMMON PURPOSES TO FOSTER THE GENERATION OF CROSS-DISCIPLINARY PROJECTS
}

\author{
Brun, Juliette (1); Salembier, Chloé (2); Loubet, Benjamin (3); Jullien, Alexandra (3)
}

1: UMR Agronomie, INRA, AgroParisTech, Université Paris-Saclay; 2: UMR SADAPT, INRA, AgroParisTech, Université Paris-Saclay; 3: UMR ECOSYS, INRA, AgroParisTech, Université ParisSaclay

\begin{abstract}
Despite the increasing demand to develop cross-disciplinary research projects, designing collaborative research still prove to be difficult due to both scientific specialization and organizational issues. In this paper, we explore how innovative design dynamics can be developed between researchers to collectively build research projects that could become common purposes for collaboration. This work relies on a case study led with the newly formed Eco\&Phy research team, who applied an innovative design process to initiate collaboration and design its scientific agenda for the next 5 years. This process was built based on both KCP and matching-building methodologies: it included an initialization phase, during which the team strategically chose topics to be explored, and exploration phases, during which researchers collectively developed new knowledge and concepts to build cross-disciplinary projects. At the end of the design process, the team had developed two new research lines that were integrated in its official agenda. In conclusion, the article discusses the relevance of design approaches to develop original collaborative research through dedicated innovation processes.
\end{abstract}

Keywords: Collaborative design, Design methodology, Early design phases, Cross-disciplinary research, Common purpose

Contact:

Brun, Juliette

INRA (French National Institute for Agricultural Research)

UMR Agronomie

France

juliette.brun@inra.fr

Cite this article: Brun, J., Salembier, C., Loubet, B., Jullien, A. (2019) 'Designing Collaborative Research: The

Exploration of Common Purposes to Foster the Generation of Cross-Disciplinary Projects', in Proceedings of the 22nd International Conference on Engineering Design (ICED19), Delft, The Netherlands, 5-8 August 2019. DOI:10.1017/

dsi.2019.228 


\section{INTRODUCTION}

The design of collaborative research is both a need and a challenge. If research collaborations are often seen as an opportunity to unveil new knowledge, tackle complex issues and promote innovation (Sonnenwald, 2007), their initialization proves to be difficult in practice. Especially, designing crossdisciplinary research projects that mix not only various disciplines, but also different research teams, presents both organizational and cognitive barriers. On the one hand, scientists may encounter organizational problems such as geographical distance (Maglaughlin \& Sonnenwald, 2005), coordination issues, mismatched expectations or misunderstandings (Dewulf et al., 2007). On the other hand, designing collaborative research requires a dedicated cognitive effort, especially because scientists tend to be fixed by their own knowledge and expertise (Jansson \& Smith, 1991; Vourc'h et al. 2018). In particular, since science becomes more and more specialized (Kostoff, 2002; Dewulf et al., 2007), imagining new links between disciplines, which could allow building innovative research projects, corresponds to a dedicated design activity, where both new knowledge and new ideas have to be explored (Chen et al., 2018).

This paper therefore investigates how design theory and methods could support the development of innovative collaborative research, and especially, the design of original cross-disciplinary research projects. The first section of the article presents a literature review regarding the design of both new research and new collaborations. The method section presents how we combined two innovative design methods to propose a design process that could help the newly formed Eco\&Phy research team building cross-disciplinary projects for its five-year plan. We then present the results of this experiment and discuss the relevance of design methods for the development of future collaborative research.

\section{DESIGNING COLLABORATIVE RESEARCH: LOOKING FOR INNOVATIVE COMMON PURPOSES FOR COLLABORATION}

\subsection{Collaborative research as an innovative design activity}

Scientists tend to be better designers than they commonly acknowledge: in addition to optimization and modeling, they also practice design in their daily activities, for instance, when building new measure instruments, new experimental settings, or even new theories and paradigms (Potier et al., 2015). According to Glanville (1999), design as a "way of understanding, acting, looking, and searching" is indeed "the key to research". Furthermore, "research has to be designed" (Glanville, 1999).

In the same way, scientists also design collaborations: collaborative research corresponds to a dedicated design process, which aims at mixing several expertises - and often several disciplines - to tackle complex issues and foster innovation. According to Sonnenwald (2007), collaborative research involves four successive steps: a foundation stage (during which collaboration is considered), a formulation stage (collaborative research projects are initiated and planned), a sustainment stage (during which research is developed over a period of time) and a conclusion stage (results are achieved and disseminated).

In this paper, we mainly focus on the foundation stage during which new research projects are designed and their main properties are defined (whereas research projects will be developed during the next stages). Moreover, when this foundation stage promotes the design of a radically new research project, we consider that it corresponds to an innovative design activity (Hatchuel and Weil, 2009), which aims at inventing something that did not exist yet.

Indeed, designing innovative research is one of the main objectives of scientific collaboration (Karniouchina et al., 2006; Dewulf et al., 2007; Sonnenwald, 2007). However, because it often involves developing cross-team and/or cross-disciplinary projects, the design of collaborative research encounters many barriers: on the one hand, developing such collaborative research may be difficult due to well-known organizational barriers, such as communication issues and mismatched expectations (Dewulf et al., 2007); on the other hand, the collective design of an innovative research project can prove to be very challenging cognitively: if mixing several expertises and disciplines is commonly expected to help developing innovative ideas, researchers actually tend to be fixed by their own disciplinary background (Vourc'h et al. 2018; Jansson \& Smith, 1991) and often experience difficulties when it comes to propose original research projects and imagining new potential links between disciplines (Dewulf et al., 2007; Karniouchina et al., 2006; Kostoff, 1999). 
Therefore, the design of original collaborative research could benefit from dedicated tools and methods. Especially, innovative design methods - such as the C-K method (Hatchuel and Weil, 2009) and the KCP process (Elmquist and Segrestin, 2009; Hooge et al., 2017) - have recently been applied to develop innovative research programs and foster cross-fertilization of knowledge and scientific expertise (Vourc'h et al, 2018). But if these approaches aim at fostering the development of new links between knowledge and sometimes lead to new collaborations, they do not explain how to integrate the respective expectations of researchers or the need to build consensus and common vision regarding new directions for future research: they focus rather on fostering defixation and exploring new concepts, than on building a common purpose for collaborations. However, the identification of common purposes for collaboration often appears as a necessary condition to design new partnerships between scientists.

\subsection{A new strategy to design collaborative research: The exploration of common purposes}

In research, common purposes for collaboration commonly take a wide variety of forms, such as the identification of relevant areas for data exchange or the sharing of resources, knowledge or expertise (Sonnenwald, 2007). The notion of "common purpose" has been largely developed in management studies, which have shown its strategic importance regarding the design of new collaborations and partnerships between diverse communities (Wildridge et al., 2004; Weck, 2006; Gillier et al., 2012). The common purposes may be more or less innovative and are not always well-defined from the very beginning of the collaboration. In this case, it has been shown that innovative design approaches and theories may also help stakeholders achieving the design of new common purposes (Gillier et al., 2010, 2012).

In the same way, during the foundation stage of new partnerships in research, the common purpose for collaboration is not always well defined from the very beginning: especially, when the collaboration aims at developing cross-disciplinary research programs, the common purpose for collaboration will arise from the identification of innovative research topics, which could be common topics of interest for the involved scientists and have to be designed during the foundation stage (Sonnenwald, 2007; Vourc'h et al., 2018). The collective design of such common purposes requires building radically new research questions and therefore corresponds to an innovative design activity (Hatchuel and Weil, 2009), which might benefit from dedicated tools and methods to overcome both cognitive and organizational barriers. But if several design methods have already been developed to explore innovative common purposes to promote collaboration in industry (Gillier et al., 2010, 2012), they have rarely been applied by research centers to design new research questions that could favor the development of common purposes for scientific collaboration.

\subsection{Research question}

In this paper, we therefore investigate the following research question: How the exploration of new common purposes for collaboration could help fostering the design of innovative research projects?

The next section presents our material and methodological framework. Especially, it details how we rely on $\mathrm{C}-\mathrm{K}$ design theory to propose a design process that could foster the collective design of new common purposes for collaborative research. The results section then presents an application of this design process with the exploration led by the Eco\&Phy research team to design innovative cross-disciplinary research projects that could become new purposes for collaboration within the newly formed team. In conclusion, we discuss the results of this case study and present further lines of development.

\section{DESIGNING COLLABORATIVE RESEARCH WITH C-K THEORY AND METHODS}

\subsection{Material: The Eco\&Phy initiative}

This work relies on a single case study: the study of an initiative led within the ECOSYS research unit (an INRA/AgroParisTech Mixed Research Unit). ECOSYS is composed of three research teams: Soil Science, Ecotoxicology and Eco\&Phy. The study focuses on an innovative design process followed by Eco\&Phy to design new research programs. 


\subsubsection{Context of the single-case study}

The newly formed team Eco\&Phy, which resulted from the fusion of two former ECOSYS teams with different disciplinary backgrounds - Ecophysiology on the one hand, and Physics and chemistry at the soil plant atmosphere interfaces on the other hand -, had to design its research agenda for the next five years in an official evaluation context (the HCERES five-year assessment). For this new research agenda, the Eco\&Phy team had to show that researchers from the two former teams were willing to work together with the proposal of cross-disciplinary research projects. In this context, two researchers of the Eco\&Phy team asked researchers in innovative design to help them build a design process that could foster the exploration of innovative cross-disciplinary research projects.

\subsubsection{Data collection with intervention research}

The data collection process was led following an intervention research approach (Radaelli et al., 2014): the main objective of intervention research is to provide both relevant results for practitioners and new theoretical knowledge for academia. Our research work presented the same dual goal: (1) it had to provide the Eco\&Phy team with a design process allowing the generation of cross-disciplinary projects that could foster collaboration within the team and be included in the official evaluation, and (2) it aimed at investigating the relevance of designing common purposes to allow building innovative crossdisciplinary research projects, which has not been addressed before by the management literature.

In our case study, in order to propose a relevant design process for the team, the two researchers in innovative design relied on design literature and methods, and especially on previous - although rare experiments led to design research projects based on existing design methods. They presented their methodology to the team and played the role of facilitators throughout all the process stages. The two researchers also gathered all the data generated during the process (from the content of the preparation sessions to the ideas generated in design workshop): some data were their own notes and presentations (especially during preparatory phases), others corresponded to data provided by the workshop participants and gathered by the two researchers (for instance, project scenarios written on specific forms were collected at the end of the design session). The detail of our research material will be presented along Section 3.2. and Section 4 in correspondence with the design process stages in order to facilitate reading.

\subsubsection{Research objectives}

The study especially followed two main research objectives:

1. Understanding how design approaches could help developing collaborative research and identifying common purposes for collaboration in a scientific context. Our hypothesis was that an exploration to design new research projects could help the team overcome both cognitive and organizational barriers to collaborative research.

2. Developing a design process that could be relevant to design new research, at the scale of the team, with the objective to produce cross-disciplinary projects; as well as testing and discussing the relevance of this process. Here, we chose to rely on innovative design methods that had already been developed to design common purposes in industrial contexts on the one hand, and to design research projects on the other hand, both categories of methods sharing a common theoretical framework: C-K design theory.

\subsection{Method: A C-K-based process for the design of collaborative research}

When the purposes for collaboration are not well-defined, studies have shown that innovative design approaches and theories may help stakeholders achieving the design of new common purposes (Gillier et al., 2010, 2012). Among them, the $\mathbf{C}-\mathbf{K}$ theory (Hatchuel and Weil, 2009) offers a framework to build methods addressing both cognitive and organizational barriers to innovative design. In this section, we first present $\mathrm{C}-\mathrm{K}$ theory, and then explain how we combined two C-K-based methods to build a process addressing the design of new collaborative research projects.

\subsubsection{C-K theory: A generic framework to build innovative design processes}

C-K theory (Hatchuel and Weil, 2009) distinguishes two spaces: the $\mathbf{C}$-space (or Concept space) and the $\mathbf{K}$-space (or Knowledge space). $\mathrm{C}$ is the space of ideas: it includes verbal statements without logical status (it is impossible to say if the statement is true or false, or if its object exists or not). The 
K-space however includes statements with a logical status (the statement is either true or false, its object exists or does not exist). For instance, the proposition "coffee" will belong to K, whereas "childhood coffee" will belong to C (without further knowledge, it is impossible to say if such object exists or not). According to C-K theory, innovation emerges from a dialog between Concepts and Knowledge, which leads to a co-expansion of the C-space and the K-space (Hatchuel and Weil, 2009). The Figure 1 below illustrates these dynamics of co-expansion with the initial concept "a naturally pink chocolate": to develop such concept, knowledge regarding the different existing types of chocolate (dark, white and milk chocolate) may be mobilized before opening a first conceptual path: for instance, white chocolate "using pink food coloring" (Figure 1). To invent a "naturally pink" chocolate, another strategy may be explored: "avoiding pink food coloring". Such constraint will involve acquiring new knowledge: for instance, knowledge regarding cocoa pods with natural shades of pink. A new transformation process can then be used to enhance this natural shade of pink and create a "natural" pink chocolate. (This concept corresponds to the Ruby chocolate: the fourth official type of chocolate, which was introduced in 2017 by the Barry Callebaut company). The corresponding C-K-map (Figure 1) shows how innovation emerges from a co-expansion of the C-space and $\mathrm{K}$-space.

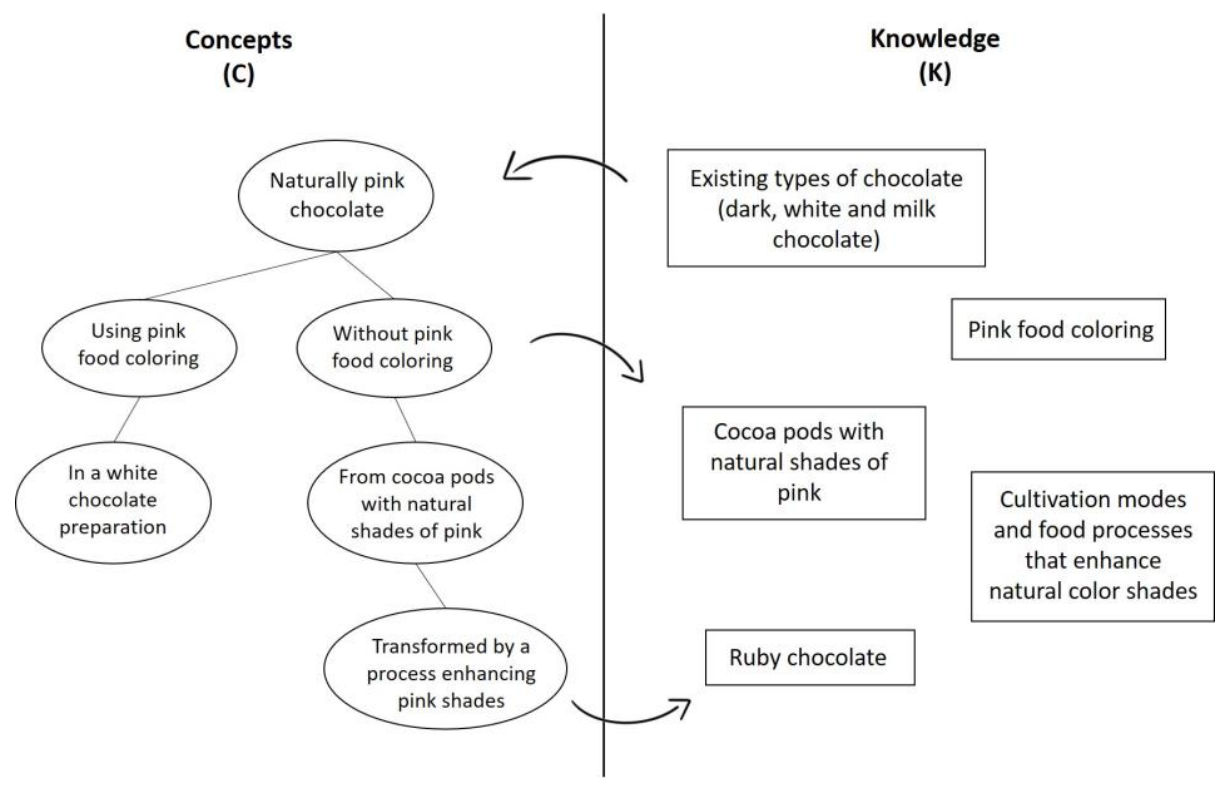

Figure 1. The C-K dynamics: a co-expansion of concepts and knowledge

\subsubsection{Combining KCP and Matching-Building processes for the collective exploration of common purposes for collaboration}

$\mathrm{C}-\mathrm{K}$ theory has often been used as a framework to propose new innovation methods: the $\mathrm{C}-\mathrm{K}$ map, for instance, is used to foster the development of disruptive ideas and original concepts paths, thus tackling fixation effects (Hatchuel and Weil, 2009). To support the collective design of common purposes for collaborative research, we especially relied on two C-K-based methods: KCP (Elmquist and Segrestin, 2009) and OPERA (Gillier et al., 2010).

The KCP process distinguishes a Definition phase, a Knowledge phase, a Concept phase and a Project phase (Elmquist and Segrestin, 2009; Vourc'h et al., 2018): during the Definition phase, a C-K map is built by a select committee to explore the innovation topic and help organizing the K-phase - where both state-of-the art knowledge and disruptive knowledge are presented to a group of participants and the C-phase - where participants explore new ideas while brainstorming in sub-groups -. The $\mathrm{KCP}$ method thus helps developing an innovative design reasoning in a collective context without necessarily showing C-K maps to the participants (Figure 2): the C-K map is only used by the select committee to prepare the content of collective workshops and to manage the progression of participants' design reasoning during the workshops. 


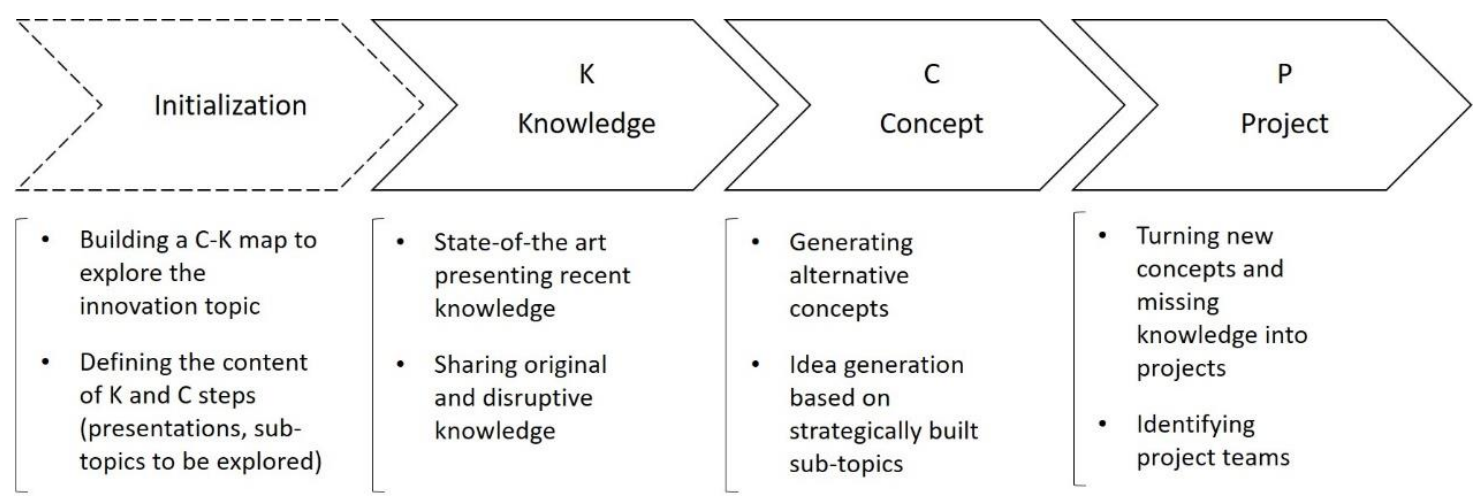

Figure 2. The four main steps of the KCP process

On another note, the OPERA method (Gillier et al., 2010) aims at reducing the uncertainty and instability of co-explorations by mapping innovative concepts and associated knowledge that could present a common value for different fields. To facilitate the formulation of common purposes (common concepts of interest for collaboration), C-K maps are built according to matching and building strategies: Concept matching and Knowledge matching consist in identifying common original concepts and missing knowledge that could be of interest for all stakeholders, while Concept building and Knowledge building consist in developing these paths (Gillier et al., 2010).

In order to help researchers collectively design new common purposes for collaboration, especially new common research questions, this research work proposes to combine KCP and OPERA logics: especially, the next sub-section presents how we relied on both KCP and OPERA to build an innovation process that could help the Eco\&Phy team exploring innovative research projects that could become common purposes for collaboration within the newly formed research team.

\subsubsection{An innovative design process to explore common purposes for collaborative research}

This design process, which consisted in a collective exploration of common purposes for collaborative research, was organized by a steering committee of four researchers: a researcher in Ecophysiology (also corresponding researcher in Ecophysiology for Eco\&Phy), a researcher in Physics and Chemistry at the soil plant atmosphere interfaces (also Eco\&Phy team leader), and two researchers in Innovative design. The main objective of the process was to help the researchers of the Eco\&Phy team to collectively design research projects for its next five-year agenda, and especially projects which could mix scientists from the two former teams, and hence, from different disciplines. Due to the official evaluation context and the short deadline for the agenda submission, it was decided that the different sessions of the process would be held during a short period of time (between November 2017 and February 2018) and that the full team will gather during a one-day workshop in early February 2018. Relying on the KCP logic, the innovative design process distinguished four steps:

Initialization phase- To prepare a collective design workshop for Eco\&Phy researchers and define its content, the steering committee relied on the KCP preparation phase: first, the main topic of the workshop was defined as "Towards Soil-plant-atmosphere-land interactions Engineering". This concept indeed allowed addressing the two main disciplinary backgrounds of the team - ecophysiology and physics and chemistry at the soil plant atmosphere interfaces - and to easily mobilize researchers from the two former teams. Starting with this initial concept, the steering committee built a first C-K tree to identify various and original concept paths, as well as relevant missing knowledge. This $\mathrm{C}-\mathrm{K}$ map was built according to a matching-building methodology (Gillier et al., 2010), which aimed to systematically formulate ideas that could be interesting for both researchers in ecophysiology and researchers in Physics and Chemistry of interfaces, and therefore ensure the generation of concepts addressing common purposes for collaboration.

Then, a collective work was led during a half-day session to challenge this first $\mathrm{C}-\mathrm{K}$ map. This session gathered the steering committee and a small group of Eco\&Phy researchers (with a total of 10 participants). The aim of this session was to discuss the map (modify and develop it), identify new innovative concepts and organize the agenda of the one-day workshop, which will gather the full research team. The expansion of the $\mathrm{C}-\mathrm{K}$ map was systematically led to foster the emergence of potential common purposes. The extended map (see the Results section) then allowed identifying interesting knowledge that could be presented to the participants during the workshop. It also helped 
building specific exploration sub-topics, which we call "spotlights". The goal of the spotlights is to propose original statements to the workshop participants - such as "Augmented vegetation cover" or "A microbiome that differentiates"- as a starting point for collective exploration and idea generation. The one-day workshop was then organized as a small KCP process: the session began with knowledge sharing and continued with concept generation sessions. The result section presents the detail of the workshops' agenda (Table 1).

Knowledge-phase - The workshop was planned to begin with a presentation of recent results regarding Soil-plant-atmosphere-land interactions (see the workshop's agenda in Table 1). The aim of this presentation was to provide participants with information that could be used to generate original propositions during the concept phase. The Knowledge-phase also relied on a one-day seminar held the day before the team collective workshop: this seminar presented knowledge regarding recent plant research.

Concept-phase - After the K-phase, participants entered in the Concept generation phase. This phase consisted in brainstorming sessions to explore "spotlight" concepts in sub-groups (according to a KCP methodology). The spotlights helped fostering divergence and idea quantity while exploring new projects ideas and new research questions.

Project-phase - The brainstorming sessions of the C-phase were directly followed by an initiation of the Project-phase. It consisted in selecting the most interesting concepts and knowledge gaps to develop scenarios of actual research projects, which could include theses, experimentations or new studies. After the workshop, further work was then led by the team to integrate these first drafts of project ideas into research lines to be included within the team research agenda and presented at the evaluation.

The following section presents the results of the initialization phase, details the workshop agenda and explains how the spotlights concepts were selected. It then presents the outputs of the collective oneday workshop - especially the concept paths and research questions generated during the process -, as well as two research projects, which arose from the workshop and were then included in the new research agenda of the team.

\section{A COLLECTIVE EXPLORATION LEADING TO THE DESIGN OF CROSS- DISCIPLINARY RESEARCH PROJECTS}

\subsection{Result presentation: From an exploration of common purposes to the proposal of new research projects}

This section presents the results obtained at each phase of the design process.

Initialization phase - During the initialization phase, the $\mathrm{C}-\mathrm{K}$ map built by the steering committee, and then extended by the enlarged group, started with the initial concept "Engineering of Soil-plantatmosphere-land interactions". The C-K map distinguished three main innovation paths around three concepts that were carefully chosen to avoid mobilizing vocabulary specific to one of the two former teams. Especially, during the half-day work session led by the enlarged group on the C-K map, it was decided to replace the word "interface" by the word "interaction" in several concepts of the maps: "interface" was indeed seen as referring to Physics and Chemistry at the soil plant atmosphere interfaces, and therefore seemed to exclude researchers in ecophysiology, whereas it was meant to be generic in the concepts of the C-K map. Such work regarding concepts formulation prevented building paths concerning only one of the two former teams, which would have hindered the exploration of common purposes for collaboration. In the final C-K map - also called control map -, the three paths were:

- Engineering of Soil-plant-atmosphere-land interactions, which models interactions

- Engineering of Soil-plant-atmosphere-land interactions, which optimizes interactions

- $\quad$ Engineering of Soil-plant-atmosphere-land interactions, which designs interactions

The first conceptual levels of the control map are presented in Figure 3. The whole control map had seven conceptual levels in total. We used a color code proposed by Hooge et al. (2012) to distinguish different levels of concept breakthrough and knowledge robustness. This color code was also challenged by the enlarged group during the half-day session in order to match with the team's knowledge referential. 


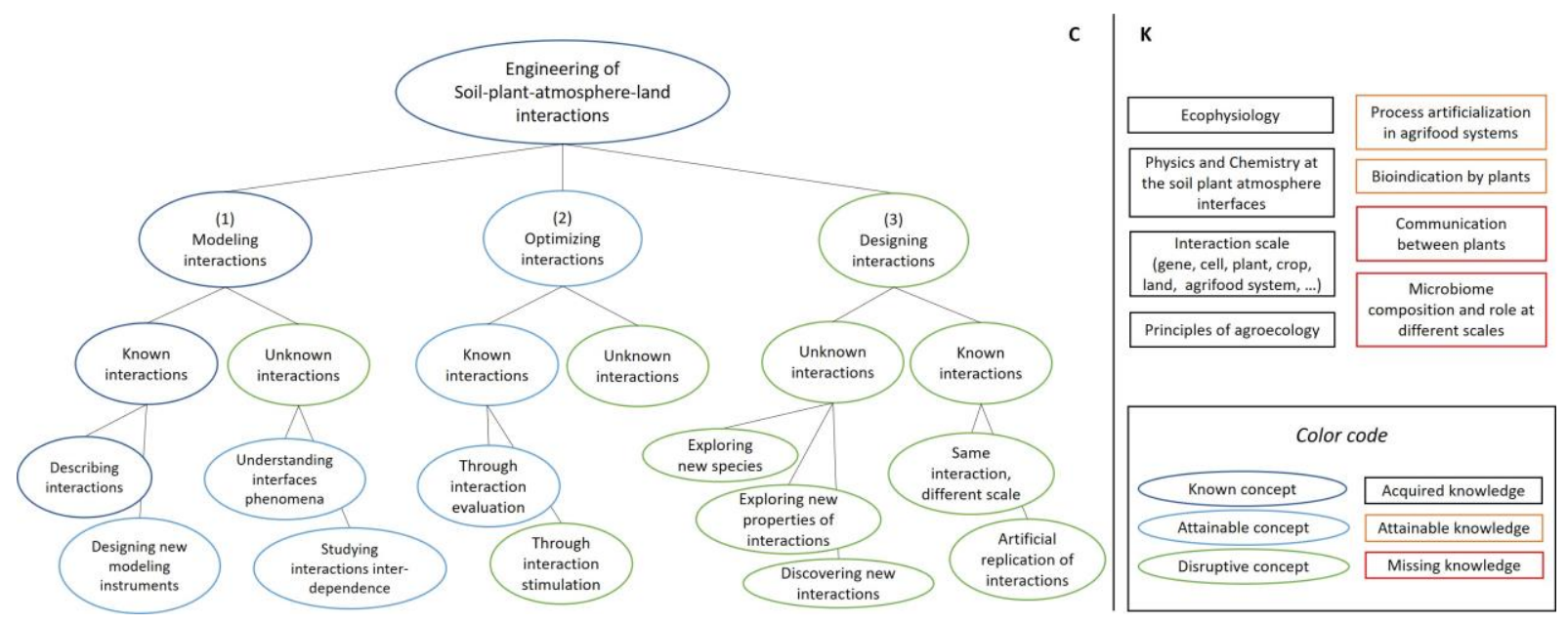

Figure 3. The first levels of the control map, which was used to prepare and manage the one-day workshop

From the control map, the enlarged group identified 6 Spotlight concepts, which could guide exploration and defixation during the $\mathrm{C}$-phase and foster the identification of common purposes:

- "Techniques to integrate complexity in the agroecosystem" (Spotlight 1)

- "Communication promoting resilience" (Spotlight 2)

- "Augmented vegetation cover" (Spotlight 3)

- "A healthy and sustainable territorial metabolism" (Spotlight 4)

- "A microbiome that differentiates " (Spotlight 5)

- "Symbiotic vegetation cover" (Spotlight 6, meant to continue the exploration led with Spotlight 3)

The agenda of the one-day workshop (Table 1) was then built to ensure mobilization of participants from the two former teams and introduce original knowledge addressing the spotlights concepts.

Table 1. The design workshop agenda

\begin{tabular}{|c|c|c|c|}
\hline \multirow{2}{*}{$\begin{array}{l}\text { Knowledge } \\
\text { sharing } \\
\text { (K-phase) }\end{array}$} & \multicolumn{3}{|c|}{$\begin{array}{l}\text { Presentation } 1 \text { - "General introduction: Towards Soil-plant-atmosphere-land } \\
\text { interactions Engineering" (including a presentation of C-K, KCP and OPERA) }\end{array}$} \\
\hline & \multicolumn{3}{|c|}{ Presentation 2 - "The role of sounds in soil-plant interactions" } \\
\hline \multirow[t]{2}{*}{$\begin{array}{l}\text { Concept } \\
\text { generation } \\
\text { (C-phase) }\end{array}$} & $\begin{array}{c}\text { Spotlight 1 } \\
\text { "Techniques to integrate } \\
\text { complexity in the agroecosystem" }\end{array}$ & $\begin{array}{l}\text { Spotlight } 2 \\
\text { "Communication } \\
\text { promoting resilience" }\end{array}$ & $\begin{array}{c}\text { Spotlight } 3 \\
\text { "Augmented } \\
\text { vegetation cover" }\end{array}$ \\
\hline & $\begin{array}{c}\text { Spotlight } 4 \\
\text { "A healthy and sustainable } \\
\text { territorial metabolism" }\end{array}$ & $\begin{array}{l}\text { Spotlight } 5 \\
\text { "A microbiome that } \\
\text { differentiates" }\end{array}$ & $\begin{array}{c}\text { Spotlight } 6 \\
\text { "Symbiotic vegetation } \\
\text { cover" }\end{array}$ \\
\hline
\end{tabular}

Knowledge, Concept and Project-phases - The one-day workshop gathered 18 team members and the two researchers in Innovative Design, which played the role of facilitators during the workshop. The session began with a general introduction and a presentation given by an external researcher, who is expert in AI and studies plant behavior. This Knowledge-phase lasted one hour and half.

Then, during the Concept-phase, participants explored spotlights concepts in sub-groups: during a first round - which lasted $2 \mathrm{~h} 15$ in total -, three sub-groups respectively explored Spotlights 1, 2 and 3 and during a second round - which also lasted $2 \mathrm{~h} 15$-, three different sub-groups explored Spotlights 4, 5 and 6. At the beginning of the concept phase, participants were remembered the key rules of brainstorming sessions and asked to avoid negative judgements regarding new ideas. At the beginning of each round, the facilitators presented the Spotlights concepts by describing pre-designed mood boards, which were meant to help participants begin their exploration (the mood board presented provocative knowledge meant to foster defixation). During each round, participants explored new ideas (1h15-long step), select one or two ideas of research projects to further describe them by filling a dedicated form (30 min-long step and beginning of the Project-phase). At the end of each round, the sub-groups were asked to present their exploration (i.e. the different categories of ideas generated) and to explain the scenarios of the selected projects (30-min long phase in total). The Table 2 presents the projects generated in relation with the spotlight concepts (noted S1, S2,..., S6). 
Table 2. Projects proposals and correspondence with the spotlights and research lines

\begin{tabular}{|l|l|c|}
\hline $\begin{array}{l}\text { S1 - "Techniques to integrate } \\
\text { complexity in the agroecosystem" }\end{array}$ & $\begin{array}{l}\text { Project "Pesticides-fertilizer-pathogens interaction in } \\
\text { landscapes" }\end{array}$ & RL3 \\
\hline $\begin{array}{l}\text { S2 - "Communication promoting } \\
\text { resilience" }\end{array}$ & Project "Crying for healing" & RL1 \\
\cline { 2 - 3 } & Project "Plants in love" & RL1 \\
\cline { 2 - 3 } Project "Nitrogen Social network" & RL1 \\
\hline $\begin{array}{l}\text { S4 - "Augmented vegetation cover" } \\
\text { territorial metabolism" }\end{array}$ & Project "Ecosystem services vs. Greenhouse Gases" & RL3 \\
\hline $\begin{array}{l}\text { S5 - "A microbiome that } \\
\text { differentiates" }\end{array}$ & Project "Promoting diversity for sustainable lands" & $/$ \\
\hline S6 - "Symbiotic vegetation cover" & $\begin{array}{l}\text { Project "Continuous formation on microbiome and } \\
\text { plants behavior relationships" (training course) }\end{array}$ & $/$ \\
\hline
\end{tabular}

After this one-day workshop, researchers directly started to work from the projects proposals to write new research lines for the new official agenda (Project-phase). The team indicated an important amount of work regarding the appropriation of the workshop outputs and their translation into research lines for its next five-year plan. Especially, the researchers carefully chose new vocabulary to be included into the research lines for the official evaluation, which required further discussion. The projects proposals allowed building two new research lines (the correspondence with the research lines was indicated by a member of the Eco\&Phy team and can be seen in Table 2). These two research lines (noted RL1 and RL3 in Table 3) corresponded to innovative common purposes for collaboration between scientists of the two former teams and managed to rely on their two disciplinary backgrounds.

Table 3. The four research lines of the team's new research agenda

\begin{tabular}{|c|l|}
\hline $\begin{array}{c}\text { RL1 } \\
\text { (workshop output) }\end{array}$ & $\begin{array}{l}\text { Biological regulations and communication in crops: Identification of key } \\
\text { processes driving the yield and resilience of bio-diverse canopies }\end{array}$ \\
\hline RL2 & $\begin{array}{l}\text { Addressing emerging challenges in our understanding of processes involved } \\
\text { in plant-soil-atmosphere interactions }\end{array}$ \\
\hline $\begin{array}{c}\text { RL3 } \\
\text { (workshop output) }\end{array}$ & $\begin{array}{l}\text { Biophysical interactions in multifunctional landscapes: How the } \\
\text { diversity of land cover, organization and management of a territory can } \\
\text { be manipulated to promote resilience and sustainability? }\end{array}$ \\
\hline RL4 & Towards larger scales and integrative studies \\
\hline
\end{tabular}

\subsection{Discussion and implications: Design approaches to build original collaborative research}

Innovative design methods - such as $\mathrm{C}-\mathrm{K}$ and $\mathrm{KCP}$ - have been recently applied to develop crossdisciplinary research programs (Vourc'h et al, 2018). In addition to fostering defixation and crossfertilization of knowledge, studies have shown that design approaches can also ensure the identification of common purposes for collaboration (Gillier et al., 2010), which is a necessary condition for collaborative research (Sonnenwald, 2007). Our case study confirms the relevance of design approaches to build innovative cross-disciplinary research projects, but also highlights their potential in building consensus on research orientation. Moreover, such approaches could be suited not only to foster collaborative research in academic research, but also in industrial contexts.

\section{CONCLUSION}

In this paper, we explained how we mobilized design theory and methodologies to help researchers from diverse disciplinary backgrounds to collectively build common purposes for future collaboration. To help the newly formed Eco\&Phy research team developing its research agenda for the next five years, we built a dedicated design process relying on two C-K-based methodologies: the KCP-process and the OPERA method. During the design process, researchers in Ecophysiology and researchers studying Physics and Chemistry at the soil plant atmosphere interfaces collectively explored new concepts of research projects, which could become common purposes for future collaboration. In order to start building a new shared vocabulary and identifying common desirable concepts, the use of 
vocabulary specific to each scientific discipline was especially avoided. At the end of the process, the team had designed several concepts of new projects and developed two new cross-disciplinary research lines, which were included in its official agenda. Therefore, organizing a dialog between researchers according to an innovative design approach successfully allowed scientists from different disciplines to identify new common purposes for future collaboration.

\section{REFERENCES}

Chen, M., Aknin, P., Lagadec, L. R., Laousse, D., Masson, P. and Weil, B. (2017), "Designing the missing link between science and industry: Organizing partnership based on dual generativity", In International Conference on Engineering Design, Vancouver, Canada.

Dewulf, A., François, G., Pahl-Wostl, C. and Taillieu, T. (2007), “A framing approach to cross-disciplinary research collaboration: experiences from a large-scale research project on adaptive water management", Ecology and Society, Vol. 12 No. 2.

Elmquist, M. and Segrestin, B. (2009), "Sustainable development through innovative design: lessons from the KCP method experimented with an automotive firm", International Journal of Automotive Technology and Management, Vol. 9 No. 2, pp. 229-244. https://doi.org/10.1504/IJATM.2009.026399

Gillier, T., Piat, G., Roussel, B. and Truchot, P. (2010), "Managing Innovation Fields in a Cross-Industry Exploratory Partnership with C-K Design Theory", Journal of Product Innovation Management, Vol. 27 No. 6, pp. 883-896. https://doi.org/10.1111/j.1540-5885.2010.00758.x

Gillier, T., Kazakci, A. O. and Piat, G. (2012), "The generation of common purpose in innovation partnerships: a design perspective”, European Journal of Innovation Management, Vol. 15 No. 3, pp. 372-392.

Hatchuel, A. and Weil, B. (2009), "CK design theory: an advanced formulation", Research in Engineering Design, Vol. 19 No. 4, p. 181.

Hooge, S., Agogué, M. and Gillier, T. (2012), “A new methodology for advanced engineering design: Lessons from experimenting CK Theory driven tools”, In International Design Conference-Design 2012.

Jansson, D. G. and Smith, S. M. (1991), “Design fixation”, Design Studies, Vol. 12 No. 1, pp. 3-11. https://doi.org/10.1016/0142-694X(91)90003-F

Karniouchina, E. V., Victorino, L. and Verma, R. (2006), "Product and service innovation: Ideas for future cross-disciplinary research", Journal of Product Innovation Management, Vol. 23 No. 3, pp. 274-280. https://doi.org/10.1111/j.1540-5885.2006.00198.x

Kostoff, R. N. (1999), “Science and technology innovation”, Technovation, Vol. 19 No. 10, pp. 593-604. https://doi.org/10.1016/S0166-4972(99)00084-X

Kostoff, R. N. (2002), “Overcoming specialization”, BioScience, Vol. 52 No. 10, pp. 937-941. https://doi.org/10.1641/0006-3568(2002)052[0937:OS]2.0.CO;2

Maglaughlin, K. L. and Sonnenwald, D. H. (2005), "Factors that impact interdisciplinary scientific research collaboration: Focus on the natural sciences in academia", In: Proceeding of the 10th International Conference of the International Society for Scientometrics and Informetrics.

Potier, O., Brun, J., Le Masson, P. and Weil, B. (2015), "How innovative design can contribute to Chemical and Process Engineering development? Opening new innovation paths by applying the C-K method", Chemical Engineering Research and Design, Vol. 103, pp. 108-122. https://doi.org/10.1016/j.cherd.2015.05.040

Radaelli, G., Guerci, M., Cirella, S. and Shani, A.B. (2014), "Intervention research as management research in practice: learning from a case in the fashion design industry", British Journal of Management, Vol. 25 No. 2, pp. 335-351. https://doi.org/10.1111/j.1467-8551.2012.00844.x

Sonnenwald, D. H. (2007), "Scientific collaboration”, Annual Review of Information Science and Technology, Vol. 41 No. 1, pp. 643-681. https://doi.org/10.1002/aris.2007.1440410121

Vourc'h, G., Brun, J., Ducrot, C., Cosson, J.F., Le Masson, P. and Weil, B. (2018), "Using design theory to foster innovative cross-disciplinary research: lessons learned from a research network focused on antimicrobial use and animal microbes' resistance to antimicrobials", Veterinary and Animal Science, Vol. 6, pp. 11-12. https://doi.org/10.1016/j.vas.2018.04.001

Weck, M. (2006), "Knowledge creation and exploitation in collaborative R\&D projects: lessons learned on success factors", Knowledge and Process Management, Vol. 13 No. 4, pp. 252-263. https://doi.org/10.1002/kpm.261

Wildridge, V., Childs, S., Cawthra, L. and Madge, B. (2004), "How to create successful partnerships-a review of the literature", Health Information \& Libraries Journal, Vol. 21, pp. 3-19. https://doi.org/10.1111/j.1740-3324.2004.00497.x

\section{ACKNOWLEDGMENTS}

This work was carried out under the umbrella of IDEAS (Initiative for Design in Agrifood Systems) and was co-funded by Eco\&Phy and the INDISS project of the BASC LabEx. 